\title{
Limitations of using feline coronavirus spike protein gene mutations to diagnose feline infectious peritonitis
}

\author{
Emily N. Barker ${ }^{*}$, Angelica Stranieri ${ }^{2}$, Chris R. Helps ${ }^{1}$, Emily L. Porter ${ }^{1}$, Andrew D. Davidson³ ${ }^{3}$ Michael J. Day ${ }^{1}$, \\ Toby Knowles ${ }^{1}$, Anja Kipar ${ }^{4,5}$ and Séverine Tasker ${ }^{1}$
}

\begin{abstract}
Feline infectious peritonitis (FIP) is a fatal disease of cats, and a sequela of systemic feline coronavirus (FCoV) infection. Mutations in the viral spike (S) gene have been associated with FCoVs found in tissues from cats with FIP, but not FCoVs found in faeces from healthy cats, and are implicated in monocyte/macrophage tropism and systemic spread. This study was designed to determine whether $\mathbf{S}$ gene mutation analysis can reliably diagnose FIP. Cats were categorised as with FIP $(n=57)$ or without FIP $(n=45)$ based on gross post-mortem and histopathological examination including immunohistochemistry for FCoV antigen. RNA was purified from available tissue, fluid and faeces. Reverse-transcriptase quantitative-PCR (RT-qPCR) was performed on all samples using FCoV-specific primers, followed by sequencing of a section of the $S$ gene on RT-qPCR positive samples. Samples were available from a total of 102 cats. Tissue, fluid, and faecal samples from cats with FIP were more likely to be FCoV RT-qPCR-positive (90.4, 78.4 and $64.6 \%$ respectively) than those from cats without FIP (7.8, 2.1 and 20\% respectively). Identification of $S$ gene mutated FCoVs as an additional step to the detection of FCoV alone, only moderately increased specificity for tissue samples (from 92.6 to 94.6\%) but specificity was unchanged for fluid samples (97.9\%) for FIP diagnosis; however, sensitivity was markedly decreased for tissue (from 89.8 to $80.9 \%$ ) and fluid samples (from 78.4 to 60\%) for FIP diagnosis. These findings demonstrate that $\mathrm{S}$ gene mutation analysis in FCoVs does not substantially improve the ability to diagnose FIP as compared to detection of FCoV alone.
\end{abstract}

\section{Introduction}

Feline coronavirus (FCoV) infection is ubiquitous in domestic cats, with up to $90 \%$ of cats within multicat households being infected [1,2]. The majority of FCoV infections are asymptomatic or are associated with mild intestinal disease. However, an estimated 1 to $5 \%$ of infected cats develop feline infectious peritonitis (FIP) [3, 4], characterised by the development of a variable combination of pyogranulomatous polyserositis, vasculitis and granulomatous lesions in organs, and an extremely high mortality rate [5, 6]. Avirulent or self-limiting FCoV infection was believed to be confined to the intestines, but we now know that healthy FCoV-infected cats can

\footnotetext{
*Correspondence: emi.barker@bristol.ac.uk

1 School of Veterinary Sciences, University of Bristol, Bristol, UK

Full list of author information is available at the end of the article
}

have systemic FCoV infection, albeit with lower FCoV viral loads than cats with FIP [7-10].

There are two different serotypes of $\mathrm{FCoV}$, both of which can cause FIP. Serotype 1 FCoVs are wholly feline viruses, whereas serotype $2 \mathrm{FCoVs}$ have arisen from recombination events between serotype $1 \mathrm{FCoVs}$ and canine coronavirus $(\mathrm{CCoV})$, involving genes encoding the $\mathrm{C}$-terminal section of the replicase complex, spike protein, non-structural accessory proteins $3 \mathrm{a}-\mathrm{c}$, and part of the envelope protein [11]. There is worldwide geographical variation in the relative distribution of serotype 1 and 2 , and co-infections can occur [12-17].

The "reference standard" for the definite diagnosis of FIP is the demonstration of FCoV antigen within histological specimens of the lesions consistent with FIP, usually by immunohistochemistry (IHC) [5]. As IHC requires an invasive sampling procedure, and has significant cost and time 
implications, alternative diagnostic techniques have been investigated, such as detection of $\mathrm{FCoV}$ and characterisation of $\mathrm{FCoV}$ genomic sequences, using pyrosequencing, Sanger sequencing or sequence specific hydrolysis probes. Recent studies have identified mutations in the gene encoding spike (S) protein of serotype $1 \mathrm{FCoVs}$ that are implicated in monocyte/macrophage tropism [18]. Two amino acid substitutions, M1058L and/or S1060A corresponding to nucleotide mutations $23531 \mathrm{~A}>\mathrm{T} / \mathrm{C}$ and $23537 \mathrm{~T}>\mathrm{G}$ respectively in the $\mathrm{S}$ gene, together distinguished $\mathrm{FCoVs}$ found in the tissues of FIP cats from those found in the faeces of healthy cats without FIP in $>95 \%$ of cases. A subsequent study, which compared detection of FCoV by RT-qPCR alone to detection of FCoV by RT-qPCR combined with sequence analysis to confirm the presence of nucleotide mutations $23531 \mathrm{~A}>\mathrm{T} / \mathrm{C}$ and $23537 \mathrm{~T}>\mathrm{G}$, concluded that the addition of an assay for $\mathrm{S}$ gene mutation analysis did not alter the specificity of the FIP diagnosis, which was already $100 \%$, but did decrease the sensitivity from 9.4 to $6.3 \%$ for serum/plasma samples and from 72 to $64 \%$ for effusion samples [19]. However, we have shown that the nucleotide mutations $23531 \mathrm{~A}>\mathrm{T} / \mathrm{C}$ and $23537 \mathrm{~T}>\mathrm{G}$ are likely to be markers of systemic FCoV infection rather than FIP per se, being present in $91 \%$ of the FCoV-positive tissue samples from cats with FIP and $89 \%$ of the FCoV-positive tissue samples from cats without FIP [20].

The aim of this study was to analyse a larger number of tissue, fluid and faeces samples from the University of Bristol FIP Biobank to assess the usefulness of S gene mutation analysis in the diagnosis of FIP.

\section{Materials and methods}

See Figure 1 for the diagnostic pathway used in this study for sample selection.

\section{Sample collection and storage}

Post-mortem tissue samples, faeces/faecal swab and body cavity fluid, if present in excess volume, were collected from cats that were euthanized with suspected FIP or due to other systemic diseases or very rarely on behavioural grounds. Some samples were included in earlier studies [20, 21]. Collection of cerebrospinal fluid (CSF), where possible, was performed immediately following euthanasia as part of a clinical training programme and was independent of presence of presenting neurological signs, which were not specifically evaluated. Where possible age and presenting signs were recorded.

Tissue samples were collected into RNAlater (Life Technologies) within $2 \mathrm{~h}$ of death, as per manufacturers' instructions, and stored at $-80{ }^{\circ} \mathrm{C}$ pending molecular analysis. Further samples were collected into $10 \%$ neutral-buffered formalin for histological examination and IHC. The tissues collected comprised primarily mesenteric lymph nodes, liver, kidney, spleen and omentum, while other tissues (e.g. intestine, brain, lungs, pericardium, pancreas or other lymph nodes) were included based on gross pathological findings or reported clinical signs. Body cavity fluid samples (e.g. ascitic fluid, pleural fluid, pericardial fluid, aqueous humour and CSF) were collected into plain or EDTA-anticoagulant blood tubes. Where immediate storage at $-80{ }^{\circ} \mathrm{C}$ was not possible,

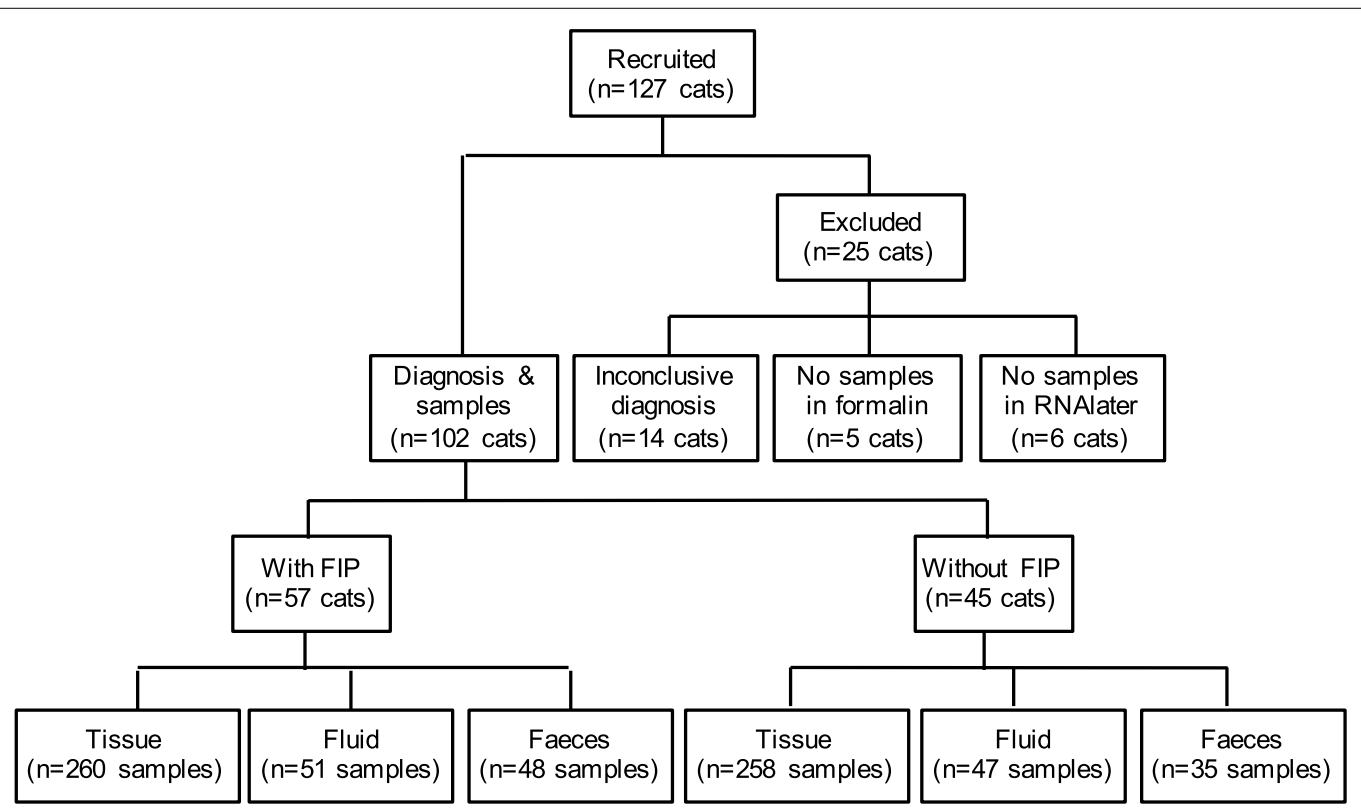

Figure 1 Diagnostic pathway used. Asterisk: Cats for which no samples were collected into formalin or RNAlater were excluded from further analysis. 
fluid was combined with RNAlater $(20 \% \mathrm{v} / \mathrm{v})$ upon collection and moved to long-term storage at $-80{ }^{\circ} \mathrm{C}$ within $24 \mathrm{~h}$ to 1 week. Faecal samples were stored immediately upon receipt at $-80^{\circ} \mathrm{C}$ until use.

\section{Histological examination and immunohistochemistry for FCoV antigen}

Formalin-fixed tissue samples were subjected to standard processing for histological examination. They were trimmed and routinely embedded in paraffin wax. Sections $(3-5 \mu \mathrm{m})$ were prepared and stained with haematoxylin-eosin, and, for the confirmation of FIP, subjected to IHC for FCoV antigen as previously described [22].

\section{Disease category}

For a cat to be assigned to the "with FIP" group, one or more tissues needed to have histopathological changes consistent with FIP, and the presence of FCoV antigen within lesional macrophages confirmed [22]. For a cat to be assigned to the "without FIP" group, gross and histopathological changes consistent with FIP needed to be absent from all tissues collected, which had to include those associated with available ante-mortem clinical findings (e.g. eye if uveitis reported). Body cavity fluid and faecal samples were classified as "with FIP" or "without FIP" on the basis of the classification of the cat from which they originated.

For cats for which FIP was considered as a differential diagnosis based on clinical history, but for which no changes supportive of FIP were present on histological examination and for which a definite alternative diagnosis was not achieved (e.g. for definitive diagnosis additional tissues should have been examined by histology), inclusion within either the FIP or without FIP groups could not be made; these cats were excluded from further analysis. Cats for which there were no samples collected into formalin or RNAlater were also excluded from further analysis.

\section{RNA extraction and RT-qPCR}

Total RNA was extracted from $20 \mathrm{mg}$ of tissue with a NucleoSpin RNA II kit (Macherey-Nagel) using methods previously described [23]. Total RNA was extracted from $100 \mu \mathrm{L}$ body cavity fluid or $10 \mathrm{mg}$ of faeces or faecal swab using either the NucleoSpin RNA II kit or using an automated platform Chemagic 360 instrument (PerkinElmer) in combination with Chemagic body fluids NA kit (Perkin-Elmer) eluted in $100 \mu \mathrm{L}$ elution buffer.

Reverse transcription was performed using a MJ Mini Gradient Thermal Cycler and ImProm II Reverse Transcriptase (Promega). Ten microlitre of total RNA were combined with ImProm II $5 \times$ Reaction Buffer, $3 \mathrm{mM}$ $\mathrm{MgCl}_{2}$, dNTPs (0.5 mM each), random hexamers (25 ng/ $\mu \mathrm{L}$ ) and ImProm II reverse transcriptase in a total volume of $20 \mu \mathrm{L}$. The following thermal profile was used; $20{ }^{\circ} \mathrm{C}$ for $5 \mathrm{~min}, 42{ }^{\circ} \mathrm{C}$ for $30 \mathrm{~min}, 70{ }^{\circ} \mathrm{C}$ for $15 \mathrm{~min}$ and $10{ }^{\circ} \mathrm{C}$ hold. The resulting $20 \mu \mathrm{L}$ of cDNA was added to $30 \mu \mathrm{L}$ of RNase-free water and stored at $-20{ }^{\circ} \mathrm{C}$. Randomly selected samples were checked for inhibition of the RT reaction using an RNA internal amplification control. No inhibition was detected (results not shown).

Quantitative PCR was performed using: $2 \times$ GoTaq Master Mix (Promega), $200 \mathrm{nM}$ forward and reverse primers (P009/P010), $25 \mathrm{nM}$ TaqMan probe (P1), $2.5 \mathrm{mM}$ $\mathrm{MgCl} 2$ and $5 \mu \mathrm{L}$ cDNA in a total volume of $25 \mu \mathrm{L}$; the following thermal profile: $95{ }^{\circ} \mathrm{C}$ for $2 \mathrm{~min}$ and 40 cycles of $95{ }^{\circ} \mathrm{C}$ for $15 \mathrm{~s}, 55^{\circ} \mathrm{C}$ for $15 \mathrm{~s}$ and $72{ }^{\circ} \mathrm{C}$ for $15 \mathrm{~s}$; in an Agilent Mx3005P qPCR System (Agilent Technologies). The primers and probe were synthesized by Metabion (Metabion International) and were described previously [24]. Fluorescence was detected at $520 \mathrm{~nm}$ during the extension phase. FCoV cDNA was used as a positive control and RNase-free water as a negative control. Relative FCoV copy number per reaction was calculated for positive samples, as previously described [20].

\section{$S$ gene mutation analysis by pyrosequencing}

Samples that were positive by FCoV RT-qPCR then underwent conventional PCR to amplify a 153 base-pair (bp) DNA fragment encompassing amino acid positions M1058L and S1060A in the S protein gene of serotype 1 $\mathrm{FCoV}$, and subsequent pyrosequencing of the amplicon. Amplification and sequencing primers (Table 1) were designed using a combination of PyroMark assay design software (Qiagen), Primer3 [25] and MFold [26], and were made by Eurofins (MWG Operon) or Metabion. Degeneracies were added to the primers, and the location of the primers optimised, based upon a sequence alignment comprised of all available serotype $1 \mathrm{FCoV}$ genomes (data not shown). Briefly, PCR was performed using: $2 \times$ GoTaq Master Mix (Promega), $200 \mathrm{nM}$ forward and biotinylated reverse primers (F614/R766), $5 \mu \mathrm{L}$ cDNA in a total volume of $25 \mu \mathrm{L}$; the following thermal profile: $95{ }^{\circ} \mathrm{C}$ for $2 \mathrm{~min}, 40$ cycles of $95{ }^{\circ} \mathrm{C}$ for $15 \mathrm{~s}, 52^{\circ} \mathrm{C}$ for $20 \mathrm{~s}$ and $72{ }^{\circ} \mathrm{C}$ for $20 \mathrm{~s}$, before being held at $10{ }^{\circ} \mathrm{C}$; in a MJ Mini Gradient Thermal Cycler. Samples that failed to produce definitive sequence data were pyrosequenced following repeat amplification using the same PCR protocol with 50 cycles of amplification.

Pyrosequencing was performed as previously described [20] using either PyroMark Q24 (Qiagen) or Pyromark Q96 (Qiagen) platforms. The dispensation order of the nucleotides was defined as; CGCTCATG for nucleotide position 23531 and CGACTGC for nucleotide position 23537.

All samples sequenced were genotyped at the nucleotide position 23531. All samples wild-type (i.e. adenine) 
Table 1 Primer and probe sequences used in this study

\begin{tabular}{lll}
\hline Name & Use & Sequence $\mathbf{( 5}^{\prime}-\mathbf{3}^{\prime} \mathbf{)}$ \\
\hline P009 & qPCR forward primer & AGCAACTACTGCCACRGGAT \\
P010 & qPCR reverse primer & GGAAGGTTCATCTCCCCAGT \\
TaqMan-P1 & FCov qPCR fluorescent probe & FAM-AATGGCCACACAGGGACAACGC-BHQ1 \\
F614 & Forward pyrosequencing primer & GCHCARTATTAYAATGGCATAATGG \\
R766 & Biotinylated reverse pyrosequencing primer & BIO-AAGYCTRGCYTGYACTTGCAT \\
S680 & M1058L pyrosequencing primer & ACAGCCTCDTTAATAGGVGGTATG \\
S693A & S1060A pyrosequencing primer & TAGGRGGTATGGCYWTGG \\
FCoV S2 F1 & Forward FCoV type 2 spike gene fragment amplification primer & TCTGCTGCCATCAAAATCAC \\
FCoV S2 R3 & Reverse FCoV type 2 spike gene fragment amplification primer & CGATGTGTAAGCAATTGTCCA
\end{tabular}

qPCR: quantitative polymerase chain reaction, FCoV: feline coronavirus, FAM: fluorescein amidite, BHQ1: black hole quencher-1, BIO: biotin.

at nucleotide position 23531, and selected mutated samples, were subjected to sequencing at nucleotide position 23537. Sequencing results were classified as non-mutated FCoV or mutated FCoV on the basis of absence or presence, respectively, of nucleotide mutations 23531A $>\mathrm{T} / \mathrm{C}$ (M1058L) and 23537T>G (S1060A).

\section{S gene mutation analysis by Sanger sequencing}

Samples that failed to produce definitive pyrosequencing data were subjected to agarose gel $(1 \% \mathrm{w} / \mathrm{v})$ electrophoresis, using ethidium bromide stain, with EasyLadder I (50 ng/band; Bioline, London, UK) and analysed using a GelDoc-It ${ }^{\circledR}$ Imaging System (UVP LLC, Cambridge, UK) to confirm that a single amplicon of the correct size (153 bp) had been produced using primers F614/ R766 (PCR as described above). Samples that produced a 153 bp amplicon were subjected to Sanger sequencing. Sequencing was performed using non-biotinylated amplification primers in a standard protocol (DNA Sequencing and Services, http://www.dnaseq.co.uk).

\section{Amplification of serotype 2 FCoV cDNA}

Samples that were positive by FCoV RT-qPCR, with a threshold cycle $\geq 36$ (relative copy number $\leq 15$ ), but that did not generate a 153 bp amplicon using primers F614/R766 were subjected to PCR to determine the presence of serotype 2 FCoVs. Primers were designed to amplify $\mathrm{a} \approx 1820 \mathrm{bp}$ fragment encompassing the S1 region of the $\mathrm{S}$ protein gene of serotype $2 \mathrm{FCoVs}$, as previously described [27]. Briefly, PCR was performed using: $2 \times$ GoTaq Master Mix (Promega), $400 \mathrm{nM}$ forward and reverse primers (FCoV S2 F1/FCoV S2 R3), $5 \mu \mathrm{L}$ cDNA in a total volume of $25 \mu \mathrm{L}$; the following thermal profile: $95{ }^{\circ} \mathrm{C}$ for $2 \mathrm{~min}, 45$ cycles of $95^{\circ} \mathrm{C}$ for $15 \mathrm{~s}, 55^{\circ} \mathrm{C}$ for $20 \mathrm{~s}$ and $72{ }^{\circ} \mathrm{C}$ for $2 \mathrm{~min}$, followed by $72{ }^{\circ} \mathrm{C}$ for $5 \mathrm{~min}$ before being held at $10{ }^{\circ} \mathrm{C}$; in an Agilent Thermal Cycler (Agilent Technologies). Positive and negative PCR controls were included in each reaction. Reaction products were separated by agarose gel electrophoresis to confirm that a single amplicon of the correct size was produced. One reaction product from each cat was subjected to a standard Sanger sequencing protocol using the amplification primers as sequencing primers.

\section{Statistical analysis}

Data [comprising: cat identification number; age; diagnosis (with FIP vs without FIP); sample type (tissue, fluid and faeces) and specific organ/body cavity of origin where applicable; histopathology result (absence vs. presence of changes consistent with FIP); IHC result (absence vs. presence of FCoV antigen in lesions); FCoV RT-qPCR result; relative $\mathrm{FCoV}$ copy number; $\mathrm{S}$ protein mutation analysis result (non-mutated vs mutated vs serotype 2 vs. failed)] were entered into a database (Excel 2008, Microsoft; Additional file 1) and exported into IBM SPSS Statistics software (version 23.0). Continuous variables within the data sets were evaluated for normal distribution using the Kolmogorov-Smirnov test. Non-normally distributed data were described as median and range (minimum and maximum values). Population proportions were compared using Chi squared test. Data evaluating FCoV relative copy numbers in tissue and faecal samples from cats with and without FIP were analysed using a multilevel modelling approach (MLwiN v3) [28] to account for the repeated measures within cats. An alternative, simplified analysis was also employed in which non-parametric Mann-Whitney U tests were used to test for differences between cats on the individual measurements. The conclusions drawn from both analyses were in full agreement (data not shown), so the simpler Mann-Whitney U test analysis is presented here. Relative copy numbers were compared between the cats with FIP and cats without FIP for different sample types (tissue, fluid and faeces). Significance was assigned at a level of $p<0.05$.

To determine the usefulness of a combined "FCoV RTqPCR and sequencing result" in the diagnosis of FIP: a sample was considered to have a positive result if a FCoV RT-qPCR-positive result was followed by detection of 
mutated FCoV, either alone or mixed with non-mutated FCoVs; and a sample was considered to have a negative result if a FCoV RT-qPCR-negative result was obtained or a FCoV RT-qPCR-positive result was obtained followed by either detection of non-mutated $\mathrm{FCoV}$ or a failure to sequence the target sequence. Sensitivity was defined as the number of the samples from cats with FIP that were deemed positive based on the method under test (e.g. IHC, RT-qPCR, or combined RT-qPCR and S gene sequencing) out of the total number of samples from cats with FIP. Specificity was defined as the number of samples from cats without FIP that were deemed negative based on the method under test out of the total number of samples from cats without FIP. Accuracy was defined as the number of samples from cats with FIP that were deemed positive combined with the number of samples from cats without FIP that were deemed negative based on the method under test out of the total number of samples available.

\section{Results}

Samples were available from 127 cats (Figure 2); for 102 of these, a definitive diagnosis was achieved (full details of the samples and results-Additional file 1): 57 cats with FIP; and 45 cats without FIP. Of the 25 cats excluded, five had no tissue samples collected into formalin, six had no tissue samples collected into RNAlater; and 14 only had limited tissue samples collected into formalin such that FIP could not be definitively diagnosed or excluded. Of the cats without FIP the reason for euthanasia and postmortem diagnosis comprised: neoplasia in 16; inflammatory/infectious (not FIP) disease in 15; metabolic disease in four; cardiac in 1; immune-mediated in 2; miscellaneous in 6; and on behavioural grounds in 1 .

Of the cats with FIP, the median age at euthanasia was 9 months (range 2-144 months; 8 cats had indeterminate age). Of the cats without FIP median age at euthanasia was 96 months (range 4-180 months; two cats had indeterminate age). Cats without FIP were significantly older than cats with FIP $(\mathrm{U}=207, p \leq 0.001)$. When available, 1-10 tissue samples (median 5 samples per cat) and/or 1 to 4 fluid samples (median 1 sample per cat) were examined per cat. See Table 2 for origin of samples and summary of RT-qPCR results.

Of the 320 FCoV RT-qPCR-positive samples subjected to $\mathrm{S}$ gene mutation analysis $272(85.0 \%)$ were successfully pyrosequenced ( $n=89$ at nucleotide 23531 alone, for M1058L; $n=183$ at nucleotides 23531 and 23537, for M1058L and S1060A), 21 (6.6\%) required Sanger sequencing, and 27 (8.4\%) failed target gene sequencing. For the outcome of S gene analysis of FCoV RT-qPCRpositive samples see Table 3 (individual results can be found in Additional file 1).

\section{Tissue sample analysis}

Tissues from cats with FIP were more likely to be FCoV RT-qPCR-positive than tissues from cats without FIP (see Table 2; $90.4 \%(235 / 260)$ vs. $7.7 \%(20 / 258) ; \chi^{2}=353.8$, $p \leq 0.001$ ), and with a greater relative FCoV copy number (median $8.3 \times 10^{3}$ vs. 25 ; $\mathrm{U}=2161.5, p \leq 0.001$ ).

\section{Cats with FIP}

Immunohistochemistry data were available for 224 of the 260 tissue samples, histopathological data alone were available for one further tissue sample and no histopathological data were available for 35 tissue samples from cats with FIP. Of the 57 cats with FIP, 56 (98.2\%) had at least one tissue sample that was FCoV RT-qPCR-positive. One cat (\#74) with severe pyogranulomatous lymphadenitis and pleuritis in association with $\mathrm{FCoV}$ antigen in intralesional macrophages, consistent with FIP, tested negative for FCoV by RT-qPCRs on all tissues. However, the use of alternative PCR primers detected $\mathrm{FCoV}$ in three of the four tissue samples available for analysis, whilst sequencing revealed mutations at the RT-qPCR primers (P009; P010) and probe (P1) binding sites. Four other tissue samples from three cats (\#61, \#94, and \#96) that had histopathological changes consistent with FIP, and were positive for $\mathrm{FCoV}$ antigen by $\mathrm{IHC}$, but negative for $\mathrm{FCoV}$ by RT-qPCR, had limited, focal changes as confirmed by the histological examination. Tissues with histopathological changes (incl. IHC) consistent with FIP were more likely $\left(\mathrm{x}^{2}=10.9, p \leq 0.001\right)$ to be FCoV RT-qPCRpositive (132/139) than those without (69/85), and with a greater relative FCoV copy number $(\mathrm{U}=2472.5$, $p \leq 0.001$; Table 4).

$\mathrm{S}$ gene mutation analysis was performed on 222 of the 235 FCoV RT-qPCR-positive samples, of which 16 (7.1\%) failed target gene sequencing. Four of the 16 samples that failed target gene sequencing were collected from two cats (\#45 and \#127) for which analysis of other tissue samples indicated the presence of mutated virus. These four samples had very low relative $\mathrm{FCoV}$ copy numbers (relative FCoV copy number $\leq 19$; see Table 3 ). Twelve of the 16 samples that failed sequencing were from five cats (\#82, \#92, \#145, \#146, and \#147), all tissues had relative FCoV copy numbers ( $\geq 41$; see Table 3 ) that were expected to be successful at sequencing; additional PCRs of these samples revealed the presence of serotype 2 FCoV. Only one of these cats (\#92) had evidence of a nonmutated, serotype $1 \mathrm{FCoV}$ in another tissue sample. All of the cats found to have serotype $2 \mathrm{FCoVs}$ were either resident in Greece (\#145, \#146, and \#147), were imported to the UK from Greece (\#82), or were suspected of having been in contact with a cat imported to the UK from Greece that was euthanased with suspected FIP (\#92). The origin of the remainder of the cats contained within 


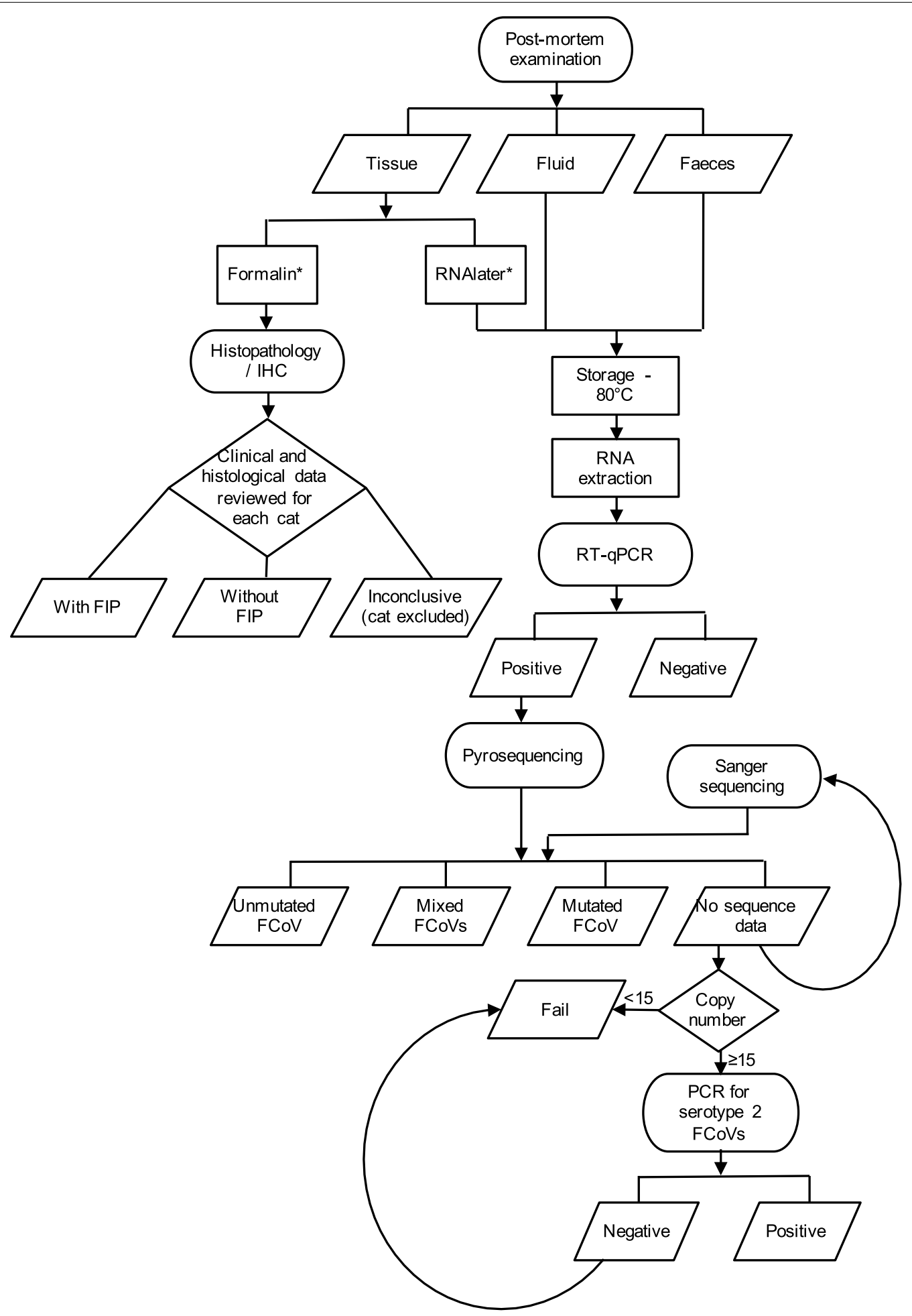

Figure 2 Distribution of samples available for analysis in the Bristol FIP Biobank.

the Bristol FIP Biobank, where known, was the UK. Four tissue samples from three cats (\#92, \#97 and \#103) had non-mutated FCoVs present in mesenteric lymph node $(n=2)$, liver $(n=1)$ and/or spleen $(n=1)$ : one cat (\#97) had mutated FCoV in another tissue sample; one cat (\#103) had both mutated and non-mutated FCoVs 
Table 2 Origin of samples, RT-qPCR results and threshold cycle values

\begin{tabular}{|c|c|c|c|}
\hline Sample source & $\begin{array}{l}\text { Number of samples analysed } \\
\text { by RT-qPCR }\end{array}$ & $\begin{array}{l}\text { RT-qPCR positive result } \\
\text { (\%) }\end{array}$ & $\begin{array}{l}\text { Threshold cycle for positive samples-median; } \\
\text { range (relative copy number-median; range) }\end{array}$ \\
\hline \multicolumn{4}{|l|}{ Cats with FIP } \\
\hline Tissue & 260 & $235(90.4)$ & $26.2 ; 12.4$ to $39.7\left(1.1 \times 10^{4} ; 1.2 \times 10^{8}\right.$ to 1.2$)$ \\
\hline Fluid & 51 & $40(78.4)$ & $31.2 ; 19.4$ to $38.5\left(373 ; 1.1 \times 10^{6}\right.$ to 2.7$)$ \\
\hline Body cavity fluid & 35 & $32(91.4)$ & $30.9 ; 19.4$ to $38.5\left(457 ; 1.2 \times 10^{8}\right.$ to 1.2$)$ \\
\hline Abdominal & 23 & $21(91.3)$ & $30.8 ; 22.2$ to $38.5\left(488 ; 1.6 \times 10^{5}\right.$ to 2.7$)$ \\
\hline Pleural & 9 & $9(100.0)$ & $29.6 ; 19.4$ to $35.0\left(1.1 \times 10^{-3} 1.2 \times 10^{8}\right.$ to 29$)$ \\
\hline Pericardial & 2 & $1(50.0)$ & $38.5(2.7)$ \\
\hline Unrecorded & 1 & $1(100.0)$ & $37.0(7.5)$ \\
\hline CSF & $14^{\mathrm{a}}$ & $7(50.0)$ & $34.8 ; 27.9$ to $36.5\left(33 ; 3.4 \times 10^{3}\right.$ to 11$)$ \\
\hline Aqueous humour & 2 & $1(50.0)$ & $33.7(6.9)$ \\
\hline Faeces & 48 & $31(64.6)$ & $30.9 ; 15.8$ to $39.7\left(457 ; 1.2 \times 10^{7}\right.$ to 1.2$)$ \\
\hline Whole faeces & 42 & $28(66.7)$ & $31.0 ; 15.8$ to $37.7\left(427 ; 1.2 \times 10^{7}\right.$ to 4.7$)$ \\
\hline Faecal swab & 6 & $3(50.0)$ & $30.5 ; 30.5$ to $39.7(598 ; 598$ to 1.2$)$ \\
\hline \multicolumn{4}{|l|}{ Cats without FIP } \\
\hline Tissue & 258 & $20(7.8)$ & $36.2 ; 26.4$ to $38.5\left(12.9 ; 9.4 \times 10^{3}\right.$ to 2.7$)$ \\
\hline Fluid & 47 & $1(2.1)$ & $36.4(11)$ \\
\hline Body cavity & 28 & $1(3.6)$ & $36.4(11)$ \\
\hline Abdominal & 13 & $1(7.8)$ & $36.4(11)$ \\
\hline Pleural & 12 & 0 & \\
\hline Pericardial & 3 & 0 & \\
\hline CSF & 19 & 0 & \\
\hline Faeces & 35 & $7(20.0)$ & \\
\hline Whole faeces & 33 & $7(20.0)$ & $33.6 ; 25.7$ to $38.6\left(74 ; 1.5 \times 10^{4}\right.$ to 2.6$)$ \\
\hline Faecal swab & 2 & 0 & $33.6 ; 25.7$ to $38.6\left(74 ; 1.5 \times 10^{4}\right.$ to 2.6$)$ \\
\hline
\end{tabular}

${ }^{a}$ All but one sample was obtained from the cerebellomedullary cistern, one sample was collected from the lumbar subarachnoid space.

detected in other tissues; and one cat (\#92) had serotype $2 \mathrm{FCoV}$ in another tissue sample. Ten tissue samples from three cats (\#43, \#70 and \#103) had sequence data consistent with the presence of both non-mutated and mutated (nucleotide 23531A $>$ T/C) FCoVs, these comprised mesenteric lymph node $(n=1)$, liver $(n=3)$, omentum $(n=2)$, spleen $(n=2)$, lung $(n=1)$ and kidney $(n=1)$ : one cat (\#103) had non-mutated FCoV sequence in another tissue sample; and one cat (\#43) had mutated FCoVs detected in other tissues. Two tissue samples from one cat (\#79) had sequence data consistent with the presence of either non-mutated and double-mutated (nucleotides 23531A $>\mathrm{T}$ and 23537T $>\mathrm{G}$ in the same sample) FCoVs or both types of mutated FCoVs; these comprised omentum and spleen $(n=2)$, which also had mutated FCoV detected in another tissue. These mixed FCoVs were not further characterised (i.e. as double or single mutants). Only mutated FCoVs were detected in 190 samples: 186 with the M1058L mutation (nucleotide $23531 \mathrm{~A}>\mathrm{T} n=151$; nucleotide $23531 \mathrm{~A}>\mathrm{C} n=31$; mixed, nucleotides $23531 \mathrm{~A}>\mathrm{T}$ and $23531 \mathrm{~A}>\mathrm{C} n=4$ ); and four with the S1060A mutation. In five of the cats $(8.8 \%$;
$\# 37$, \#43, \#70, \#100, and \#101) different mutations were detected in different tissues.

\section{Cats without FIP}

Of the 45 cats without FIP, 12 (26.7\%) had at least one tissue positive for FCoV by RT-qPCR; IHC was negative for 11 of these 12 cats, and not available for the 12 th cat $(\# 80$, unstable diabetic, no histopathological findings suggestive of FIP). Histopathological and IHC data were available for 181 of the 258 tissue samples, histopathological data alone were available for 77 further tissue samples. For all cats without FIP, histopathological examination did not find changes suggestive of FIP and all were IHCnegative. Of those samples with available IHC 10.5 percent were FCoV RT-qPCR-positive (see Table 4). Of the FCoV RT-qPCR-positive samples, three (15.8\%) failed $\mathrm{S}$ gene mutation analysis and were collected from three cats (cats \#80, \#91 and \#141); all had very low relative FCoV copy numbers ( $\leq 11$; see Table 3$)$.

Two tissue samples had non-mutated FCoVs present; these comprised colon and brain from one cat (\#56, pyothorax and pyogranulomatous bronchopneumonia), 
Table 3 Outcome of target gene sequencing of RT-qPCR FCoV-positive samples

\begin{tabular}{|c|c|c|}
\hline $\begin{array}{l}\text { Sample source (number of RT- } \\
\text { qPCR positive samples) }\end{array}$ & $\begin{array}{l}\text { Outcome of target gene } \\
\text { sequencing }\end{array}$ & $\begin{array}{l}\text { Sequencing result (number of samples; median, and range, relative copy num- } \\
\text { ber per reaction) }\end{array}$ \\
\hline \multicolumn{3}{|l|}{ Cats with FIP } \\
\hline \multirow[t]{2}{*}{ Tissue $(n=222)^{\mathrm{a}}$} & Success $(n=206)$ & $\begin{array}{l}\text { Non-mutated FCoVs }\left(n=4 ; 337,2.6 \times 10^{5} \text { to } 5.4\right) \\
\text { Mixed non-mutated and mutated FCoVs }\left(n=12 ; 1.1 \times 10^{3}, 2.3 \times 10^{6} \text { to } 33\right) \\
\text { M1058L }\left(n=10 ; 731,4.4 \times 10^{5} \text { to } 33\right) \\
\text { Double-mutated FCoVs }(\mathrm{M} 1058 \mathrm{~L} \text { and S1060A) or mixed mutated FCoVs }(n=2 \text {; } \\
\left.2.3 \times 10^{6} \text { and } 7.6 \times 10^{4}\right) \\
\text { Mutated FCoVs }\left(n=190 ; 1.3 \times 10^{4}, 1.2 \times 10^{8} \text { to } 1.2\right) \\
\text { M1058L }\left(n=186 ; 1.4 \times 10^{4}, 1.2 \times 10^{8} \text { to } 1.2\right) \\
\text { S1060A }\left(n=4 ; 1.8 \times 10^{4}, 9.0 \times 10^{6} \text { to } 4.2 \times 10^{3}\right)\end{array}$ \\
\hline & Failure $(n=16)$ & $\begin{array}{l}\text { Low copy number ( } n=4 ; 6.2,19 \text { to } 4.1) \\
\text { Presence of serotype } 2 \mathrm{FCoVs}\left(n=12 ; 8.3 \times 10^{3}, 2.5 \times 10^{7} \text { to } 41\right)\end{array}$ \\
\hline \multirow[t]{2}{*}{ Fluid $(n=39)^{b}$} & Success $(n=34)$ & $\begin{array}{l}\text { Non-mutated FCoVs }\left(n=4 ; 190,1.3 \times 10^{3} \text { to } 41\right) \\
\text { Mixed non-mutated and mutated (M1058L) FCoVs }\left(n=4 ; 15,1.1 \times 10^{3} \text { to } 5.8\right) \\
\text { Mutated FCoVs }\left(n=26 ; 457,1.1 \times 10^{6} \text { to } 2.7\right) \\
\text { M1058L }\left(n=25 ; 457,1.1 \times 10^{6} \text { to } 2.7\right) \\
\text { S1060A }\left(n=1 ; 3.2 \times 10^{3}\right)\end{array}$ \\
\hline & Failure $(n=5)$ & $\begin{array}{l}\text { Low copy number ( } n=1 ; 2.7) \\
\text { Presence of serotype } 2 \text { FCoVs }\left(n=4 ; 639,2.0 \times 10^{4} \text { to } 27\right)\end{array}$ \\
\hline \multirow[t]{2}{*}{ Faeces $(n=31)$} & Success $(n=29)$ & $\begin{array}{l}\text { Non-mutated FCoVs }\left(n=13 ; 1.1 \times 10^{5}, 1.2 \times 10^{7} \text { to } 285\right) \\
\text { Mixed non-mutated and mutated (M1058L) FCoVs }\left(n=2 ; 1.9 \times 10^{4} \text { and } 91\right) \\
\text { Mutated (M1058L) FCoVs }\left(n=14 ; 63,1.7 \times 10^{4} \text { to } 1.2\right)\end{array}$ \\
\hline & Failure $(n=2)$ & Presence of serotype 2 FCoVs ( $n=2 ; 178$ and 27) \\
\hline \multicolumn{3}{|l|}{ Cats without FIP } \\
\hline \multirow[t]{2}{*}{ Tissue $(n=20)$} & Success $(n=17)$ & $\begin{array}{l}\text { Non-mutated FCoVs }\left(n=2 ; 2.1 \times 10^{3} \text { and 5.0) }\right. \\
\text { Mixed non-mutated and mutated (M1058L) FCoVs }(n=1 ; 2.7) \\
\text { Mutated (M1058L) FCoVs }\left(n=14 ; 63,9.4 \times 10^{3} \text { to } 4.7\right)\end{array}$ \\
\hline & Failure $(n=3)$ & Low copy number ( $n=3 ; 5.0,11$ to 4.7$)$ \\
\hline Fluid $(n=1)$ & Success $(n=1)$ & Mutated (M1058L) FCoVs $(n=1 ; 11)$ \\
\hline \multirow[t]{2}{*}{ Faeces $(n=7)$} & Success $(n=6)$ & Non-mutated FCoVs $\left(n=6 ; 330,1.5 \times 10^{4}\right.$ to 19$)$ \\
\hline & Failure $(n=1)$ & Low copy number $(n=1 ; 2.6)$ \\
\hline
\end{tabular}

a Sequencing was not performed on 13 FCoV RT-qPCR positive tissue samples from FIP cats as no corresponding tissue in formalin were available for analysis.

${ }^{b}$ One FCoV RT-qPCR positive fluid sample was lost from analysis.

Table 4 Results of FCoV antigen immunohistochemistry and FCoV RT-qPCR for tissue from cats with FIP and cats without FIP

\begin{tabular}{|c|c|c|c|c|}
\hline \multirow[t]{2}{*}{ Tissue source } & \multirow[t]{2}{*}{ RT-qPCR } & \multicolumn{2}{|l|}{ Immunohistochemistry } & \multirow[t]{2}{*}{ Tota } \\
\hline & & Negative $^{a}$ & Positive & \\
\hline \multicolumn{5}{|l|}{ Cats with FIP } \\
\hline & Negative & 16 & 7 & 23 \\
\hline & Positive (relative copy number: median, range) & $69\left(1.2 \times 10^{3}, 1.4 \times 10^{7}\right.$ to 1.6$)$ & $132\left(4.9 \times 10^{4}, 1.2 \times 10^{8}\right.$ to 1.2$)$ & 201 \\
\hline & Total & 85 & 139 & 224 \\
\hline \multicolumn{5}{|l|}{ Cats without FIP } \\
\hline & Negative & 162 & 0 & 162 \\
\hline & Positive (relative copy number: median, range) & $19\left(16,9.4 \times 10^{3}\right.$ to 2.7$)$ & 0 & 19 \\
\hline & Total & 181 & 0 & 181 \\
\hline
\end{tabular}

a This includes 11 tissue samples with histopathological changes consistent with FIP, from cats definitively diagnosed with FIP based on analysis of additional tissue, but for which immunohistochemistry was negative (10 were positive for FCoV by RT-qPCR).

which also had mutated FCoV in the liver. One sample (colon) from one cat (\#63, central nervous system (CNS) astrocytoma) had sequence data consistent with the presence of both non-mutated and mutated (M1058L) FCoVs; no other tissues were FCoV RT-qPCR-positive. Only mutated FCoVs were detected in 14 samples, all of which had the M1058L mutation (nucleotide 23531A $>\mathrm{T} n=7$; nucleotide $23531 \mathrm{~A}>\mathrm{C} n=7$; none mixed). 


\section{Body cavity fluid samples}

Fluid from cats with FIP was more likely $\left(x^{2}=58.5\right.$, $p \leq 0.001)$ to be FCoV-positive $(n=40 / 51)$ compared to fluid from cats without FIP $(n=1 / 47)$. There were too few positive samples in the cats without FIP $(n=1)$ to compare copy numbers.

\section{Cats with FIP}

In one cat (\#94) CSF was collected from both lumbar and cisternal sites, and was FCoV RT-qPCR-positive for the cisternal sample (relative FCoV copy number 104) and negative for the lumbar sample. Brain or spinal cord from this cat was not available for histological examination.

One FCoV RT-qPCR-positive sample (\#100, pleural fluid) was lost from further analysis. Of the remaining FCoV RT-qPCR-positive samples five (12.8\%) failed target gene sequencing. One of these samples (\#98, pericardial fluid), collected from a cat with mutated $\mathrm{FCoV}$ detected in tissue samples, had a very low relative FCoV copy number (see Table 3). Four were abdominal fluids from four cats (\#82, \#145, \#146 and \#147) that had relative FCoV copy numbers ( $\geq 27$; see Table 3 ) that were expected to be successful for sequencing; further analysis revealed the presence of serotype $2 \mathrm{FCoV}$. These four cats also had serotype $2 \mathrm{FCoV}$ detected in tissue samples.

Four fluid samples had non-mutated FCoVs detected; these comprised abdominal fluid $(n=3)$ and pleural fluid $(n=1)$ from three cats (\#55, \#70 and \#93); two of which had mutated FCoVs in tissue samples (\#55 and \#93), and one of which had both non-mutated and mixed mutated FCoVs in tissue samples (\#70). Four samples had sequence data consistent with the presence of both nonmutated and mutated FCoVs; these fluids from three cats (\#37, \#79 and \#103) were of abdominal $(n=1)$, pleural $(n=2)$, and unknown origin $(n=1)$; all cats had mutated FCoVs in tissue samples. Mutated FCoVs were detected in 26 samples; 25 with the M1058L mutation (nucleotide
23531A $>\mathrm{T} n=21$; nucleotide $23531 \mathrm{~A}>\mathrm{C} n=4$ ); one with the S1060A mutation.

\section{Cats without FIP}

Only one sample of abdominal fluid from a cat (\#125) with severe interstitial pneumonia was found to be $\mathrm{FCoV}$ RT-qPCR-positive, at a low level (relative FCoV copy number 11.3; see Table 3); sequencing revealed mutated (nucleotide 23531A $>$ C) FCoV. Cytological analysis of this sample was not performed. This cat also had a low relative FCoV copy number (4.7) in a sample of lung tissue, which had the same $\mathrm{S}$ gene mutation.

\section{Faecal samples}

Faeces from cats with FIP was more likely $\left(\chi^{2}=16.2\right.$, $p \leq 0.001)$ to be FCoV RT-qPCR-positive (31/48) compared to cats without FIP (7/35), but with no difference in relative copy number $(\mathrm{U}=76, p=0.221$; FIP, median 457.6 , range 1.2 to $1.1 \times 10^{7}$; non-FIP, median 74.2 , range 2.6 to $\left.1.5 \times 10^{4}\right)$.

\section{Cats with FIP}

PCRs of the two samples that failed sequencing (\#82 and \#145) revealed the presence of serotype $2 \mathrm{FCoV}$. Both of these cats also had serotype $2 \mathrm{FCoV}$ detected in tissue and fluid samples.

\section{Cats without FIP}

The sample for which sequencing (\#115) failed had a very low relative FCoV copy number (2.6; see Table 3).

\section{Sensitivity, specificity and accuracy}

For sensitivity, specificity and accuracy of identification of FCoV by RT-qPCR alone or RT-qPCR in combination with subsequent detection of serotype 1 mutated FCoVs in the diagnosis of FIP see Table 5. There was no significant difference between cats with FIP and cats without

Table 5 Sensitivity, specificity and accuracy of diagnosis of FIP using molecular diagnostics

\begin{tabular}{lllrr}
\hline & Basis of diagnosis & Tissue $^{\mathbf{a}}$ & Fluid & Faeces \\
\hline Sensitivity \% $(n=$ positive/total) & RT-qPCR alone & $89.8(n=202 / 225)$ & $78.4(n=40 / 51)$ & $64.6(n=31 / 48)$ \\
& Combination testing & $80.9(n=182 / 225)$ & $60(n=30 / 50)^{c}$ & $33.3(n=16 / 48)$ \\
Specificity \% $(n=$ negative/total) & RT-qPCR alone & $92.6(n=239 / 258)$ & $97.9(n=46 / 47)$ & $80(n=28 / 35)$ \\
& Combination testing & $94.6(n=244 / 258)$ & $97.9(n=46 / 47)$ & $100(n=35 / 35)$ \\
Accuracy \% $(n=$ true result/total) & RT-qPCR alone & $91.3(n=441 / 483)$ & $87.8(n=86 / 98)$ & $71.1(n=59 / 83)$ \\
& Combination testing & $88.2(n=426 / 483)$ & $78.4(n=76 / 97)$ & $61.4(n=41 / 83)$ \\
\hline
\end{tabular}

The reference-standard for diagnosis of FIP was considered identification of FCoV antigen by immunohistochemistry in at least one tissue in association with appropriate histopathological changes, and cats were considered "without FIP" where FIP was excluded as a diagnosis.

a As some positive samples without histopathological data were not subjected to sequencing, only those samples with histopathological data available were included in these calculations.

b RT-qPCR in combination with spike protein sequence characterisation FCoV.

c One sample lost from analysis. 
FIP for the proportion of mutated FCoVs detected in FCoV RT-qPCR-positive tissue and fluid samples (76.2\% vs. $\left.88.9 \%) ; \chi^{2}=2.96, p=0.086\right)$.

\section{Discussion}

In total, 699 tissue, fluid and faeces samples were analysed from 102 cats, 57 with FIP and 45 without FIP. This is a marked increase in the number of samples analysed as compared to most previous studies [20,21, 29, 30], and contains similar numbers of effusion samples to two previous studies [19, 31]. Some studies have examined the use of FCoV RT-PCR alone in the diagnosis of FIP using fluid samples [29, 31]. Other studies [19, 21] compared FCoV RT-PCR to FCoV RT-PCR in combination with characterisation of $\mathrm{S}$ gene mutations in the diagnosis of FIP using body cavity fluids, these derived similar sensitivity (72 to $85 \%$ for FCoV RT-PCR alone and 60 to $64 \%$ for FCoV RT-PCR and S gene mutations characterisation) and specificity (100\% for both FCoV RT-PCR alone and FCoV RT-PCR and $\mathrm{S}$ gene mutations characterisation) as obtained in this study (sensitivity $78.4 \%$ for FCoV RTPCR alone and 60\% FCoV RT-PCR and S gene mutations characterisation; specificity 97.9 and $97.9 \%$ respectively).

As expected, in cats with histological changes consistent with FIP, individual tissues without FIP lesions were more likely to be FCoV RT-qPCR-negative or have lower copy numbers than those tissues in which FIP lesions were present. Overall, however, FCoV RT-qPCR was more sensitive ( $89.7 \%$ vs. $62.1 \%$; calculated from Table 4 ) than IHC at detecting FCoV in tissues from cats with FIP. Therefore, not surprisingly, to maximise the sensitivity of both IHC and RT-qPCR at detecting FCoV in cats with FIP, biopsies should be collected from tissues with imaging changes or gross visual changes consistent with granulomata, and from lesion sites, whenever possible. Distribution of granulomatous lesions within a tissue, and virus laden macrophages within a lesion, is not uniform, which could account for the failure to detect viral antigen in some FIP lesions, and the negative FCoV RTqPCR result in some cats in which the combined histological and IHC examination confirmed FIP. However, application of the calculated sensitivity to suspect FIP cases has to be viewed with caution, as not all samples included in the study were selected on the basis of clinical signs and gross pathological changes. In contrast, $10 \%$ of tissue samples from cats without FIP had a positive FCoV RT-qPCR result even though there were neither histological changes consistent with FIP nor was there evidence of viral antigen expression in tissue macrophages by IHC, resulting in a specificity of $90 \%$ for FCoV RT-qPCR, as compared to $100 \%$ for the reference standard of IHC. Persistence of FCoV in both intestinal and extraintestinal tissue macrophages in the absence of disease has been reported in healthy cats experimentally infected with FCoV, albeit with authors reporting IHC to be a relatively insensitive method of $\mathrm{FCoV}$ detection compared with RT-qPCR [7].

Two previous studies on cerebrospinal fluid only evaluated samples collected from the cerebellomedullary cistern $[29,30]$. One study evaluated the use of immunocytochemistry for the diagnosis of FIP; when all samples were combined there was a sensitivity of $81 \%$ and a specificity of $85 \%$ [30]. The other study evaluated the use of RT-qPCR for the diagnosis of FIP, where the sensitivity was $42 \%$, but specificity was 100 percent [29]. The results of the latter study are comparable with those of the current study (sensitivity 50\%; specificity $100 \%$ ). However, the apparent effect of the site of cerebrospinal fluid collection on diagnostic sensitivity of $\mathrm{FCoV}$ infection warrants further investigation. In cats with FIP there may be concern that some clinical signs could relate to increased intracranial pressure, where lumbar sampling could provide lower risk of herniation cf. cisternal sampling; however, FIP lesions rarely go beyond the leptomeninges of the brain stem (unpublished results).

Detection of FCoV by RT-qPCR in colonic tissue of 3 cats without FIP was not surprising as enteric infection has been described in otherwise clinically healthy cats [7, 8,32 . These 3 cats were euthanized as a result of clinical signs relating to pyothorax, brain tumour and nasal adenocarcinoma, had unremarkable histopathological examination and negative IHC of colonic tissue. In the 2 of the 3 cats where faeces were available for testing there was no detectable viral shedding. In 1 cat the FCoV was non-mutated, another cat had mutated FCoV, and in the remaining cat mixed non-mutated and mutated $\mathrm{FCoV}$ was detected. Of note, the cat with pyothorax also had non-mutated virus detected at a low level in its brain, and mutated virus detected at low level in its liver, suggesting that it was viraemic at the time of death and that the virus persisted not only in the colon but also in extraintestinal tissue macrophages [7]. If colonic tissue samples are excluded, all but one tissue sample from the non-FIP cats that were FCoV RT-qPCR-positive for which sequence data were available $(n=13)$ had mutated FCoV, confirming our previous findings that $\mathrm{S}$ gene mutations are a marker of systemic spread [20].

False-negative FCoV RT-qPCR results are possible, due to the high rate of FCoV genomic mutation, which could result in inefficient binding at the primer and/or probe sites. As only samples with FCoV RT-qPCR-positive results had pyrosequencing performed, FCoV RT-qPCRnegative results were not confirmed. However, false negative RT-qPCR results are considered to be uncommon, 
and were only detected in 1 of 57 cats with confirmed FIP in this study where at least one tissue from all the other cats were positive.

It is possible that the calculated relative $\mathrm{FCoV}$ copy numbers in this study are an overestimate of viral load. FCoV RT-qPCR assays amplify both cell-associated subgenomic mRNA, as well as cell-associated or virionassociated genomic RNA, with relative abundance determined by the positioning of primers. As viral transcription starts at the $3^{\prime}$ end of the FCoV genome there are more subgenomic mRNAs containing viral $3^{\prime}$ sequence than those containing viral $5^{\prime}$ sequence, hence assays directed at the $5^{\prime}$ end of the genome (e.g. viral replicase complex genes) are less susceptible to viral load overestimation than those directed at the $3^{\prime}$ end of the genome (e.g. 7a/b accessory protein genes). The RTqPCR assay used in the present study targets the region spanning the membrane-nucleocapsid gene junction (nucleotides positions 26655-26826 of FCoV isolate FIPV 79-1146 DQ010921) [24]. Overestimation is less of an issue in the faecal samples, firstly as faeces has a high level of bacteria, and is thus rich in RNases that would degrade any RNA released from cells shed into the gut lumen, and secondly as the viral RNA is most likely to be present in its virion form, which does not contain subgenomic mRNA and is protected from RNase degradation by the viral envelope. Any cell-associated viral RNA is likely to be degraded due to cell death and the abundant RNases. This study did not determine whether any faecally shed FCoV was infective; this is an important concept as faeces containing mutated FCoV theoretically has increased potential to cause FIP following faecooral transmission, assuming the mutated virus can enter enterocytes and replicate. Previous studies have reported 39-85\% of FCoVs detected in tissues from cats with FIP had loss of 3c gene functionality [33-35], which has been associated with a loss of ability to replicate in enterocytes and therefore infectivity via the natural route $[35,36]$. Enterocyte cell cultures have been used to more accurately assess FCoV infectivity and virus copy number in a recent study [8]. However, use of enterocyte cell cultures was not possible in this study, nor was $3 c$ gene sequencing attempted.

When calculating accuracy, the authors considered it very important to include samples for which $\mathrm{S}$ gene mutation analysis failed, as a more accurate reflection of the clinical situation where failure to identify the presence of mutated FCoVs may be considered lack of support of the diagnosis of FIP. We were not able to obtain pyrosequencing data in all samples; this was attributed to low relative FCoV copy number, failure of amplification primer binding, or failure of pyrosequencing primers to bind to viral cDNA as a result of sequence mismatches.
Conventional sequencing of the pyrosequencing amplicon was possible in 21 cases in which pyrosequencing failed ( $n=48$ of 320 samples where pyrosequencing was attempted), significant secondary structure was predicted in these amplicons at the pyrosequencing primer binding site, which could account for the failure to pyrosequence [26]. Mixed non-mutated and mutated FCoV infections may also have been missed by the pyrosequencing assay as the amplification step biases the detected sequence towards the dominant virus type. In addition, both serotype 1 and serotype 2 FCoVs have been associated with the development of FIP; however, only mutations within the $\mathrm{S}$ protein fusion peptide of the more prevalent serotype $1 \mathrm{FCoVs}$ have been associated with systemic infection and development of FIP $[18,20]$. As the recombination events that result in the formation of serotype 2 FCoVs include the $\mathrm{S}$ protein gene, assays that characterise this portion of the genome are not applicable to serotype 2 FCoVs. Therefore, it was predicted that pyrosequencing would fail for those samples containing serotype $2 \mathrm{FCoV}$; however, both serotype 1 and 2 FCoVs were detected by the RT-qPCR assay used in this study, as this assay targets a section of the genome not affected by the recombination events [24]. In this study only cats that failed pyrosequencing were assessed for the presence of serotype $2 \mathrm{FCoVs}$, therefore it cannot be excluded that more cats had a dual infection with both serotypes. Spike gene mutation analysis, in combination with FCoV RT-qPCR, results in a modest increase in specificity, but this is offset by a decrease in sensitivity resulting in decreased accuracy. Independent of disease prevalence within a population, there was no significant difference in the proportion of mutated FCoVs detected in tissue and body cavity fluid samples between cats with FIP and cats without FIP that were FCoV RT-qPCR-positive $\left(\mathrm{X}^{2}=2.96, p=0.086\right)$. Overall, the combination of FCoV RT-qPCR and S protein mutation analysis does not enhance the diagnosis of FIP over FCoV RT-qPCR alone, and S gene mutation analysis has significant time and cost implications.

It has been previously proposed that the M1058L or S1060A substitutions could affect the fusogenic activity and cell receptor specificity of the FCoV S protein [18, 20], permitting entry into macrophages and monocytes. It is further proposed that additional $\mathrm{FCoV}$ mutations, along with changes within the host's immunological response, are required to permit the seemingly uncontrolled replication seen during the development of FIP. These hypotheses are supported by the present study: firstly, the finding that the majority of FCoV detected in tissue samples from both cats with FIP and cats without FIP have M1058L or S1060A substitutions in the FCoV $\mathrm{S}$ protein; and secondly, as also described in a previous study of naturally infected cats [10], the finding that 
FCoV RNA was detected in a far greater proportion of tissue samples from cats with FIP $(90.4 \%)$ than tissue samples from cats without FIP (7.8\%), and, in those samples that were RT-qPCR positive, significantly higher FCoV relative copy numbers were found in the FIP samples (median $8.3 \times 10^{3}$ vs. $25 ; \mathrm{U}=2161.5, p \leq 0.001$ ). Other viral genomic mutations have also been associated with FIP, but were not evaluated as part of this study. For example, mutations in the $\mathrm{S}$ protein gene encoding amino acid differences in the furin cleavage motif [37] and the heptad HR1 region of the S2 subunit [38] have been correlated with disease. Truncations of the accessory protein $3 \mathrm{c}$ gene have also been associated with loss of ability to replicate within enterocytes and, as such, have only been reported in FIP-associated FCoVs [35]. However, characterisation of these viral genomic mutations was not within the aims of this study, and use of these viral genomic mutations in the diagnosis of FIP has, so far, not been suggested.

Other study limitations include lack of cytological data for fluid samples, which cannot be performed retrospectively on stored samples, and was not consistently performed at the time of collection due to lack of clinical justification in euthanased cats. However, a number of other studies have examined the use of immunocytochemistry on fluid in the diagnosis of FIP [30,39], and reported similar sensitivities for the diagnosis of FIP to the FCoV RT-qPCR used in this study, but observed increased false positive results resulting in reduced specificities. However, in our experience, false positive results are not a relevant issue, provided sufficient cell numbers can be examined; this can be achieved when cells are concentrated in cytospins or when fluids are used to prepare formalin-fixed, paraffin embedded cell pellets that can then be treated like a tissue specimen for IHC (unpublished observations; Anja Kipar) [5]. In addition, pyrosequencing was only used to target a small region of the serotype $1 \mathrm{FCoV}$ genome.

The University of Bristol FIP Biobank cats included in this study represent a convenience population, including cats for which FIP was not necessarily a differential diagnosis, and cats for which the samples available do not necessarily reflect clinical signs reported and, as such, clinically relevant samples of tissues essential for a definitive diagnosis may not be included. Differences between the cats with FIP and cats without FIP in this convenience population are clearly demonstrated when age at diagnosis is compared, which reflects the diseases for which these cats were euthanased, with neoplasia being the most common reason for euthanasia in the significantly older cats without FIP. This significant difference in the age could complicate comparison of faecal FCoV shedding between each clinical group (20\% for nonFIP vs. $64.6 \%$ for FIP group), as younger cats are more likely to have been recently exposed to factors that could increase likelihood of enteric $\mathrm{FCoV}$ infection such as multicat households (i.e. breeding cattery or rehoming shelter). One study found FCoV shedding was most common in young cats $(90 \%$ in cats aged 8-56 weeks cf. $39 \%$ for cats $>56$ weeks) [1]; however, another study of faecal FCoV shedding found no difference between different age categories $(34.6 \%<1$ year of age, $31.6 \% 1-5$ years, and $35.3 \%>5$ years) [40]. Ideally the cats without FIP would have been age and clinical sign matched to the cats with FIP; however, this was not possible and is generally very difficult to achieve in an unbiased clinical patient cohort. Previous case-controlled studies of FIP have either not reported age of either FIP or control cat populations [29, $31,41]$, or recruited healthy control cats [42]. One advantage of the increased age in the cats without FIP is that it does imply that these cats would be unlikely to have gone on to develop FIP had their concurrent disease not resulted in euthanasia. The absence of clinically relevant samples of tissue for some cats resulted in their exclusion from analysis, as a definitive diagnosis could not be achieved.

As in earlier studies using the same methodology [20, 21], the present data suggest that the presence of M1058L or S1060A substitutions in the FCoV S protein are indicative of systemic spread of $\mathrm{FCoV}$ and not a definitive marker of the development of FIP. Albeit less common than mutated FCoVs in cats with FIP, mutated FCoVs may be detected in cats without FIP, and non-mutated FCoVs may be detected in cats with FIP. Despite a slight increase in specificity of 92.6 to $94.6 \%$ for tissue samples, the addition of $\mathrm{S}$ gene mutation analysis to the detection of $\mathrm{FCoV}$ by RT-qPCR in samples from cats does not help in the differentiation of cats with and without FIP, and hence, does not aid in the clinical diagnosis of FIP.

\section{Additional file}

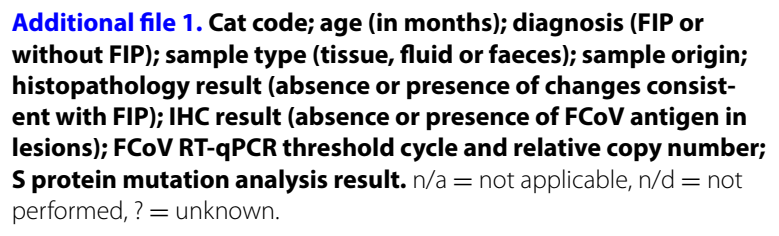

Abbreviations

bp: base pair; CCoV: canine coronavirus; CNS: central nervous system; CSF: cerebrospinal fluid; FCoV: feline coronavirus; FIP: feline infectious peritonitis; IHC: immunohistochemistry; RT-qPCR: reverse transcriptase quantitative polymerase chain reaction; $\mathrm{S}$ protein: spike protein. 


\section{Competing interests}

$\mathrm{CH}, \mathrm{MD}$ and ST work for a commercial veterinary diagnostic laboratory, Langford Vets, wholly owned by the University of Bristol, that uses molecular methods to detect viral pathogens in cats, including FCoV.

\section{Authors' contributions}

$\mathrm{ST}, \mathrm{AK}, \mathrm{AD}$, and $\mathrm{CH}$ participated in the design of the study. EB, AS, and EP carried out the in vitro experimental work. EB, AS, EP, ST, and MD obtained samples. $\mathrm{CH}$ supervised the design of the RT-qPCR and pyrosequencing assays. MD carried out the histopathological analysis. AK undertook the immunohistochemical examinations and analyses. EB, TK and ST carried out the statistical analysis. EB, EP, AK, ST and $\mathrm{CH}$ analysed the results and drafted the manuscript. All authors contributed to the writing of the manuscript. All authors read and approved the final manuscript.

\section{Acknowledgements}

The authors thank the veterinary practices, cat breeders and rescue centres that helped in the acquisition of samples used in this study. We thank our colleagues, current and past, at the Feline Centre and Veterinary Pathology Unit, Langford Vets, University of Bristol, who have assisted in obtaining postmortem samples. We thank members of the Histology Laboratory, Veterinary Laboratory Services, Institute of Veterinary Science, University of Liverpool and Institute of Veterinary Pathology, Vetsuisse Faculty, University of Zurich for technical assistance. We would also like to acknowledge Professor Stuart Siddell for his work upon which this study was built.

\section{Availability of data and materials}

The datasets supporting the conclusions of this article are included within the article (and its additional files).

\section{Consent for publication}

Not applicable.

\section{Ethics approval and consent to participate}

This was a retrospective study of samples collected with full informed consent from owners that samples could be used for research purposes. The project has been approved under ethical review by the University of Bristol Animal Welfare and Ethical Review Board (VIN/14/013).

\section{Funding}

This research was supported by a project Grant from The Petplan Charitable Trust (10-27) and by a project Grant from the Morris Animal Foundation (\#D16FE-507). Neither funding body played any role in: design of the study; collection, analysis, or interpretation of data; or writing the manuscript.

\section{Author details}

${ }^{1}$ School of Veterinary Sciences, University of Bristol, Bristol, UK. ${ }^{2}$ University of Milan, Milan, Italy. ${ }^{3}$ School of Cellular and Molecular Medicine, University of Bristol, Bristol, UK. ${ }^{4}$ Institute of Veterinary Pathology, Vetsuisse Faculty, University of Zurich, Zurich, Switzerland. ${ }^{5}$ Institute of Global Health, Faculty of Health and Life Sciences, University of Liverpool, Liverpool, UK.

\section{Publisher's Note}

Springer Nature remains neutral with regard to jurisdictional claims in published maps and institutional affiliations.

Received: 18 July 2017 Accepted: 15 September 2017

Published online: 05 October 2017

\section{References}

1. Pedersen NC, Sato R, Foley JE, Poland AM (2004) Common virus infections in cats, before and after being placed in shelters, with emphasis on feline enteric coronavirus. J Feline Med Surg 6:83-88

2. Pedersen NC (1976) Serologic studies of naturally occurring feline infectious peritonitis. Am J Vet Res 37:1449-1453

3. Addie DD, Jarrett JO (1992) Feline coronavirus antibodies in cats. Vet Rec 131:202-203
4. Addie DD, Toth S, Murray GD, Jarrett O (1995) Risk of feline infectious peritonitis in cats naturally infected with feline coronavirus. Am J Vet Res 56:429-434

5. Kipar A, Meli ML (2014) Feline infectious peritonitis: still an enigma? Vet Pathol 51:505-526

6. Pedersen NC (2014) An update on feline infectious peritonitis: diagnostics and therapeutics. Vet J 201:133-141

7. Kipar A, Meli ML, Baptiste KE, Bowker LJ, Lutz H (2010) Sites of feline coronavirus persistence in healthy cats. J Gen Virol 91:1698-1707

8. Desmarets LM, Vermeulen BL, Theuns S, Conçeicão-Neto N, Zeller M, Roukaerts ID, Acar DD, Olyslaegers DA, Van Ranst M, Matthijnssens J et al (2016) Experimental feline enteric coronavirus infection reveals an aberrant infection pattern and shedding of mutants with impaired infectivity in enterocyte cultures. Sci Rep 6:20022

9. Meli M, Kipar A, Müller C, Jenal K, Gönczi E, Borel N, Gunn-Moore D, Chalmers S, Lin F, Reinacher M, Lutz H (2004) High viral loads despite absence of clinical and pathological findings in cats experimentally infected with feline coronavirus (FCoV) type I and in naturally FCoV-infected cats. J Feline Med Surg 6:69-81

10. Kipar A, Baptiste K, Barth A, Reinacher M (2006) Natural FCoV infection: cats with FIP exhibit significantly higher viral loads than healthy infected cats. J Feline Med Surg 8:69-72

11. Herrewegh AA, Smeenk I, Horzinek MC, Rottier PJ, de Groot RJ (1998) Feline coronavirus type II strains 79-1683 and 79-1146 originate from a double recombination between feline coronavirus type I and canine coronavirus. J Virol 72:4508-4514

12. Addie DD, Schaap IA, Nicolson L, Jarrett O (2003) Persistence and transmission of natural type I feline coronavirus infection. J Gen Virol 84:2735-2744

13. Benetka V, Kübber-Heiss A, Kolodziejek J, Nowotny N, Hofmann-Parisot M, Mostl K (2004) Prevalence of feline coronavirus types I and II in cats with histopathologically verified feline infectious peritonitis. Vet Microbiol 99:31-42

14. Hohdatsu T, Okada S, Ishizuka Y, Yamada H, Koyama H (1992) The prevalence of types I and II feline coronavirus infections in cats. J Vet Med Sci 54:557-562

15. Vennema H (1999) Genetic drift and genetic shift during feline coronavirus evolution. Vet Microbiol 69:139-141

16. Kummrow M, Meli ML, Haessig M, Goenczi E, Poland A, Pedersen NC, Hofmann-Lehmann R, Lutz H (2005) Feline coronavirus serotypes 1 and 2: seroprevalence and association with disease in Switzerland. Clin Diagn Lab Immunol 12:1209-1215

17. Shiba N, Maeda K, Kato H, Mochizuki M, Iwata H (2007) Differentiation of feline coronavirus type I and II infections by virus neutralization test. Vet Microbiol 124:348-352

18. Chang HW, Egberink HF, Halpin R, Spiro DJ, Rottier PJ (2012) Spike protein fusion peptide and feline coronavirus virulence. Emerg Infect Dis 18:1089-1095

19. Felten S, Weider K, Doenges S, Gruendl S, Matiasek K, Hermanns W, Mueller E, Matiasek L, Fischer A, Weber K, Hirschberger J, Wess G, Hartmann K (2015) Detection of feline coronavirus spike gene mutations as a tool to diagnose feline infectious peritonitis. J Feline Med Surg 19:321-335

20. Porter E, Tasker S, Day MJ, Harley R, Kipar A, Siddell SG, Helps CR (2014) Amino acid changes in the spike protein of feline coronavirus correlate with systemic spread of virus from the intestine and not with feline infectious peritonitis. Vet Res 45:49

21. Longstaff L, Porter E, Crossley VJ, Hayhow SE, Helps CR, Tasker S (2017) Feline coronavirus quantitative reverse transcriptase polymerase chain reaction on effusion samples in cats with and without feline infectious peritonitis. J Feline Med Surg 19:240-245

22. Kipar A, Bellmann S, Kremendahl J, Köhler K, Reinacher M (1998) Cellular composition, coronavirus antigen expression and production of specific antibodies in lesions in feline infectious peritonitis. Vet Immunol Immunopathol 65:243-257

23. Dye C, Siddell SG (2007) Genomic RNA sequence of feline coronavirus strain FCoV C1 Je. J Feline Med Surg 9:202-213

24. Dye C, Helps CR, Siddell SG (2008) Evaluation of real-time RT-PCR for the quantification of FCoV shedding in the faeces of domestic cats. J Feline Med Surg 10:167-174

25. Rozen S, Skaletsky H (2000) Primer3 on the WWW for general users and for biologist programmers. In: Krawetz S, Misener S (eds) Bioinformatics 
methods and protocols: methods in molecular biology, vol 132. Humana Press, New York, pp 365-386

26. Zuker M (2003) Mfold web server for nucleic acid folding and hybridization prediction. Nucleic Acids Res 31:3406-3415

27. Barker EN, Tasker S, Gruffydd-Jones TJ, Tuplin CK, Burton K, Porter E, Day MJ, Harley R, Fews D, Helps CR, Siddell SG (2013) Phylogenetic analysis of feline coronavirus strains in an epizootic outbreak of feline infectious peritonitis. J Vet Intern Med 27:445-450

28. Charlton C, Rasbash J, Browne WJ, Healy M, Cameron B (2017) MLwiN Version 3.00. Centre for Multilevel, Modelling University of Bristol, Bristol

29. Doenges SJ, Weber K, Dorsch R, Fux R, Fischer A, Matiasek LA, Matiasek K, Hartmann K (2016) Detection of feline coronavirus in cerebrospinal fluid for diagnosis of feline infectious peritonitis in cats with and without neurological signs. J Feline Med Surg 18:104-109

30. Gruendl S, Matiasek K, Matiasek L, Fischer A, Felten S, Jurina K, Hartmann K (2016) Diagnostic utility of cerebrospinal fluid immunocytochemistry for diagnosis of feline infectious peritonitis manifesting in the central nervous system. J Feline Med Surg 19:576-585

31. Doenges SJ, Weber K, Dorsch R, Fux R, Hartmann K (2017) Comparison of real-time reverse transcriptase polymerase chain reaction of peripheral blood mononuclear cells, serum and cell-free body cavity effusion for the diagnosis of feline infectious peritonitis. J Feline Med Surg 19:321-335

32. Vogel $L$, Van der Lubben $M$, te Lintelo EG, Bekker CP, Geerts T, Schuijff LS, Grinwis GC, Egberink HF, Rottier PJ (2010) Pathogenic characteristics of persistent feline enteric coronavirus infection in cats. Vet Res 41:71

33. Borschensky CM, Reinacher M (2014) Mutations in the $3 \mathrm{c}$ and $7 \mathrm{~b}$ genes of feline coronavirus in spontaneously affected FIP cats. Res Vet Sci 97:333-340

34. Vennema H, Poland A, Foley J, Pedersen NC (1998) Feline infectious peritonitis viruses arise by mutation from endemic feline enteric coronaviruses. Virology 243:150-157
35. Pedersen NC, Liu HW, Scarlett J, Leutenegger CM, Golovko L, Kennedy H, Kamal FM (2012) Feline infectious peritonitis: role of the feline coronavirus $3 \mathrm{c}$ gene in intestinal tropism and pathogenicity based upon isolates from resident and adopted shelter cats. Virus Res 165:17-28

36. Pedersen NC, Liu H, Dodd KA, Pesavento PA (2009) Significance of coronavirus mutants in feces and diseased tissues of cats suffering from feline infectious peritonitis. Viruses 1:166-184

37. Licitra BN, Millet JK, Regan AD, Hamilton BS, Rinaldi VD, Duhamel GE, Whittaker GR (2013) Mutation in spike protein cleavage site and pathogenesis of feline coronavirus. Emerg Infect Dis 19:1066-1073

38. Lewis CS, Porter E, Matthews D, Kipar A, Tasker S, Helps CR, Siddell SG (2015) Genotyping coronaviruses associated with feline infectious peritonitis. J Gen Virol 96:1358-1368

39. Felten S, Matiasek K, Gruendl S, Sangl L, Wess G, Hartmann K (2017) Investigation into the utility of an immunocytochemical assay in body cavity effusions for diagnosis of feline infectious peritonitis. J Feline Med Surg 19:410-418

40. Kiss I, Kecskemeti S, Tanyi J, Klingeborn B, Belak S (2000) Prevalence and genetic pattern of feline coronaviruses in urban cat populations. Vet $J$ 159:64-70

41. Hartmann K, Binder C, Hirschberger J, Cole D, Reinacher M, Schroo S, Frost J, Egberink H, Lutz H, Hermanns W (2003) Comparison of different tests to diagnose feline infectious peritonitis. J Vet Intern Med 17:781-790

42. Paltrinieri S, Grieco V, Comazzi S, Cammarata Parodi M (2001) Laboratory profiles in cats with different pathological and immunohistochemical findings due to feline infectious peritonitis (FIP). J Feline Med Surg 3:149-159

\section{Submit your next manuscript to BioMed Central and we will help you at every step:}

- We accept pre-submission inquiries

- Our selector tool helps you to find the most relevant journal

- We provide round the clock customer support

- Convenient online submission

- Thorough peer review

- Inclusion in PubMed and all major indexing services

- Maximum visibility for your research

Submit your manuscript at www.biomedcentral.com/submit 